\title{
Intravenous administration of anti-vascular endothelial growth factor humanized monoclonal antibody bevacizumab improves articular cartilage repair
}

\author{
Toshihiro Nagai, Masato Sato, Toshiharu Kutsuna, Mami Kokubo, Goro Ebihara, Naoshi Ohta, Joji Mochida
}

\begin{abstract}
Introduction: In this study, we investigate the efficacy of repairing an osteochondral defect in rabbit knee joints by administering bevacizumab, a humanized monoclonal anti-vascular endothelial growth factor (VEGF) antibody.

Methods: An osteochondral defect was created on the patellar groove of 20 Japanese white rabbits that were classified into two recipient groups: group B, administration of bevacizumab (100-mg intravenous injection on the day of surgery and 2 weeks later), and a control group (defect only). Rabbits were killed 1 and 3 months postoperatively. Sections were stained with safranin O. Repair sites were evaluated using the modified O'Driscoll International Cartilage Repair Society grading system. The expression of chondromodulin (ChM)-I and VEGF was evaluated using immunohistochemical analyses.
\end{abstract}

Results: At 1 month postoperatively, the repair site in group B was filled with cartilaginous tissue. At 3 months, the repair site retained this cartilage phenotype. At 1 month in the controls, the defects were mainly filled with fibrous tissue. At 3 months, the defect was replaced by fibrous tissue and bone. Over the 3-month period, histological scores were significantly higher in group B than in the controls. At 1 month, group B showed intense positive results for ChM-I in the bottom of the repair tissue. VEGF was also identified in the same area. In the controls, no ChM-I was observed in the repair tissue. Conversely, the remodeling hypertrophic chondrocyte layer stained intensely for VEGF.

Conclusions: Intravenous administration of bevacizumab contributes to better repair of articular cartilage in an osteochondral defect model. We suggest the possibility of facilitating articular cartilage repair with anti-VEGF antibody rather than using cultured cells or artificial scaffolds.

\section{Introduction}

Mature articular cartilage shows limited capacity for regeneration after degeneration or injury [1]. For this reason, various treatments have been developed in anticipation of restoration by regenerative medicine. At present, techniques using penetration of subchondral bone [2-5], microfracture [6-9], mosaicplasty [10-12], cell transplantation [13-16], and implantation of tissueengineered cartilage with various scaffold materials [17-22] or without scaffold [23-27] have been developed

\footnotetext{
* Correspondence: sato-m@is.icc.u-tokai.ac.jp

Department of Orthopaedic Surgery, Surgical Science, Tokai University School of Medicine, 143 Shimokasuya, Isehara, Kanagawa 259-1193, Japan
}

to overcome this obstacle. Penetration of subchondral bone such as drilling and microfracture to be filled with reparative cells from bone marrow is a method that has been developed to stimulate spontaneous healing [18]. This procedure attempts to achieve repair via the mechanism of endochondral ossification. However, the defect to be filled with reparative cells shows a large amount of vascular invasion, and the tissue tends to be replaced by bone and a surface of fibrocartilaginous repair tissue [28].

Successful regeneration of any tissue requires the presence of reparative cells with the potential to differentiate into the phenotypes required to restore the damaged 
site, but a microenvironment that supports the proliferation and differentiation of those cells is also needed $[28,29]$. In anticipation of favorable articular cartilage repair in the osteochondral defect model, reparative cells must be provided with an environment to acquire the properties of natural articular cartilage. We recently constructed a 3-D, scaffold-free, tissue-engineered cartilage [24] and transplanted this cartilage in only the superficial layer region of the osteochondral defects as an initiator of cartilage differentiation in reparative cells [23] and achieved good restoration effects in the long term [29]. We confirmed that in the early stage of transplantation, a good restoration effect of articular cartilage is seen with reparative cells derived from marrow that acquire antiangiogenic properties [23]. We therefore hypothesized that good cartilage repair may be achieved by inhibiting the bioactivity of vascular endothelial growth factor (VEGF) in the osteochondral defect. A recent investigation examined the effect of treatment with anti-VEGF humanized monoclonal antibody (bevacizumab), which was developed as a treatment for malignant tumors [30]. Bevacizumab binds to VEGF secreted by angiogenic tumors and thereby inhibits VEGF binding to the VEGF receptor in vascular endothelial cells, reportedly restraining cancer growth by inhibiting angiogenesis [31,32].

The objective of this study is to investigate the efficacy of repair in an osteochondral defect model of the rabbit knee joint following administration of bevacizumab, a humanized monoclonal anti-VEGF antibody, without using cultured cells or artificial scaffolds.

\section{Materials and methods}

Animal experiments were approved by the ethics review board of Tokai University and were performed in accordance with the guidelines on animal use of Tokai University.

\section{Repair of the osteochondral defect}

Twenty Japanese white rabbits (female, 16-18 weeks old, weighing approximately $3 \mathrm{~kg}$ ) were used in this study. The rabbits were anesthetized by exposure to sevoflurane and $\mathrm{O}_{2}$ gas. After receiving a medial parapatellar incision to both legs, each patella was dislocated laterally and an osteochondral defect (diameter, $5 \mathrm{~mm}$; depth, $3 \mathrm{~mm}$ ) was created on the patellar groove of the femur in both legs using a drill and a biopsy punch (Kai Industries, Seki, Japan). The bottom of the subchondral bone was shaved to a plane using the biopsy punch until bleeding was seen from the marrow. Rabbits were classified into two recipient groups: Group B, with administration of bevacizumab (10 rabbits; $100-\mathrm{mg}$ intravenous injection administered on the day of surgery and 2 weeks later); and controls (10 rabbits; defect only). After recovery from surgery, all animals were allowed to walk freely in their cages without any splints.

\section{Histological evaluation of cartilage repair}

Rabbits were killed 1 and 3 months postoperatively by an overdose of intravenous anesthetic. The distal part of the femur was excised and fixed with $4 \%$ paraformaldehyde for 7 days. Each specimen was decalcified in a solution of $10 \%$ ethylenediaminetetraacetic acid (EDTA) in distilled water ( $\mathrm{pH}$ 7.4) for 2-3 weeks, then embedded in paraffin wax and sectioned perpendicularly $(4.5-\mathrm{m}$ sections) through the center of the defect. Each section was stained with safranin $O$ for glycosaminoglycans.

Immunohistochemistry was performed as described previously $[23,33]$. Briefly, sections were deparaffinized according to standard procedures. Sections were treated with $0.005 \%$ proteinase (type XXIV; Sigma-Aldrich Co., St. Louis, MO, USA) for $30 \mathrm{~min}$ at $37^{\circ} \mathrm{C}$ for antigen retrieval. For chondromodulin-I (ChM-I), primary goat polyclonal antibody (Santa Cruz Biotechnology, Santa Cruz, CA, USA) diluted 1:200 in phosphate-buffered saline (PBS) and $1 \%$ bovine serum albumin (BSA) was placed on the section overnight at $4{ }^{\circ} \mathrm{C}$. For VEGF, a primary mouse monoclonal antibody (Upstate, Lake Placid, NY, USA) diluted 1:50 in PBS and 1\% BSA was placed on the section overnight at $4^{\circ} \mathrm{C}$. Slides were washed with PBS after incubation for $1 \mathrm{~h}$ at room temperature with biotin-conjugated goat antimouse secondary antibody for VEGF and with biotin-conjugated donkey antigoat secondary antibody for ChM-I. Next, slides were treated with horseradish peroxidase-labeled streptavidin for $1 \mathrm{~h}$ and then soaked in $0.05 \%$ solution of diaminobenzidine in Tris $\mathrm{HCl}$ buffer ( $\mathrm{pH}$ 7.6) containing $0.005 \%$ hydrogen peroxide. Finally, slides were counterstained with Mayer's hematoxylin. Safranin O-stained sections were scored by two individuals under blinded conditions, according to a modified O'Driscoll [34] International Cartilage Repair Society (ICRS) grading scale [26] (Table 1).

\section{Statistical analysis}

Results are presented as the means \pm standard deviation (SD). Histological score was analyzed by the MannWhitney $U$ test. Values of $P<0.05$ were considered statistically significant for any differences.

\section{Results}

\section{Histological evaluation of repair tissue}

Operations were uneventful, and all rabbits immediately resumed normal cage activity. In Group B, major infection was identified in one knee at 1 month after surgery and in three knees at 3 months. These infected knees were omitted from the study. As a result, nine knees at 1 month and seven knees at 3 months were assessed 
Table 1 Histological grading system ${ }^{a}$

\begin{tabular}{|c|c|c|}
\hline Tissue morphology (Ti) & $\begin{array}{l}\text { Intactness of calcified cartilage layer, } \\
\text { formation of tidemark (Tide) }\end{array}$ & Lateral integration of implanted material (Latl) \\
\hline $4=$ Mostly hyaline cartilage & $\begin{array}{l}1=<25 \% \text { of the calcified cartilage layer } \\
\text { intact }\end{array}$ & $1=$ Not bonded \\
\hline $3=$ Mostly fibrocartilage & $\begin{array}{l}2=25-49 \% \text { of the calcified cartilage } \\
\text { layer intact }\end{array}$ & $2=$ Bonded at one end/partially both ends \\
\hline $2=$ Mostly noncartilage & $\begin{array}{l}3=50-75 \% \text { of the calcified cartilage } \\
\text { layer intact }\end{array}$ & $3=$ Bonded at both sides \\
\hline $1=$ Exclusively noncartilage & $\begin{array}{l}4=76-90 \% \text { of the calcified cartilage } \\
\text { layer intact }\end{array}$ & Basal integration of implanted material (Basl) \\
\hline Matrix staining (Matx) & $\begin{array}{l}5=\text { Complete intactness of the calcified } \\
\text { cartilage layer }\end{array}$ & $1=<50 \%$ \\
\hline $1=$ None & Subchondral bone formation (Bform) & $2=50-70 \%$ \\
\hline 2 = Slight & $1=$ No formation & $3=70-90 \%$ \\
\hline $3=$ Moderate & 2 = Slight & $4=91-100 \%$ \\
\hline $4=$ Strong & $3=$ Strong & Inflammation (InfH) \\
\hline Structural integrity (Stru) & $\begin{array}{l}\text { Histologic appraisal of surface } \\
\text { architecture (SurfH) }\end{array}$ & $1=$ Strong inflammation \\
\hline $1=$ Severe disintegration & $1=$ Severe fibrillation & $3=$ Slight inflammation \\
\hline $2=$ Cysts or disruption & $2=$ Moderate fibrillation & $5=$ No inflammation \\
\hline $\begin{array}{l}3=\text { No organization of } \\
\text { chondrocytes }\end{array}$ & $3=$ Slight fibrillation or irregularity & Histologic grading system (Hgtot) \\
\hline $\begin{array}{l}4=\text { Beginning of columnar } \\
\text { organization of chondrocytes }\end{array}$ & $4=$ Normal & Some of the histologic variables: \\
\hline $\begin{array}{l}5=\text { Normal, similar to healthy } \\
\text { mature cartilage }\end{array}$ & Histologic appraisal defect filling (FilH) & Tissue morphology (Ti) \\
\hline $\begin{array}{l}\text { Chondrocytes clustering in implant } \\
\text { (Clus) }\end{array}$ & $1=<25 \%$ & Matrix staining (Matx) \\
\hline $1=25-100 \%$ of cells clustered & $2=26-50 \%$ & Structural integrity (Stru) \\
\hline $2=<25 \%$ of the cells clustered & $3=51-75 \%$ & Cluster formation (Clus) \\
\hline \multirow[t]{5}{*}{$3=$ No clusters } & $4=76-90 \%$ & Tidemark opening (Tide) \\
\hline & $5=91-110 \%$ & Bone formation (Bform) \\
\hline & & Histologic surface architecture (SurfH) \\
\hline & & Histologic degree of defect filling $($ FilH) \\
\hline & & $\begin{array}{l}\text { Lateral integration of defect-filling tissue (Basl) and } \\
\text { histologic signs of inflammation ( }(\mathrm{nfH})\end{array}$ \\
\hline
\end{tabular}

'Presentation of variables and the grading system based on a modified International Cartilage Repair Society (ICRS) grading scale [26] developed by O'Driscoll, Keeley and Salter [34].

from Group B, compared to 10 knees in controls at both 1 and 3 months.

At 1 month after surgery, defects in both Group B and the controls were filled with reparative cells. In Group $B$, the repair site appeared to be filled with cartilaginous tissue, which was stained with safranin $\mathrm{O}$ (Figures 1a and $1 \mathrm{~b}$ ). Lateral integration was well bonded at both sides of the surrounding cartilage. The surface of the repair site showed several smooth fibrous cell layers, and rounded chondrocytes formed inside the repair tissue in a convex pattern. The lower portion of the repair tissue contained hypertrophic chondrocytes that were remodeling the subchondral bone. Thus, the defects showed sequential construction of abundant inhomogeneous extracellular matrix from the surface by fibrous cells (or fibrocartilage cells), rounded chondrocytes and hypertrophic chondrocytes. Similarly, in the controls, defects consisted of inhomogeneous extracellular matrix from fibrous cells (or fibrocartilage cells), rounded chondrocytes and hypertrophic chondrocytes; however, no tendency toward uniform constitution was apparent. The defect was not filled with repaired tissue (Figures 1c and 1d). At 3 months in Group B, the repair site maintained a cartilage phenotype and was well integrated with the surrounding cartilage (Figure 2). Repaired tissue showed a columnar organization. The surface of the repair site retained a smooth and convex formation similar to the surrounding cartilage. In the controls at 3 months, the repair site had been replaced with fibrous tissue and bone (Figure 3 ), and in the surrounding adjacent cartilage there was evidence of osteoarthritic changes with loss of cartilage. 

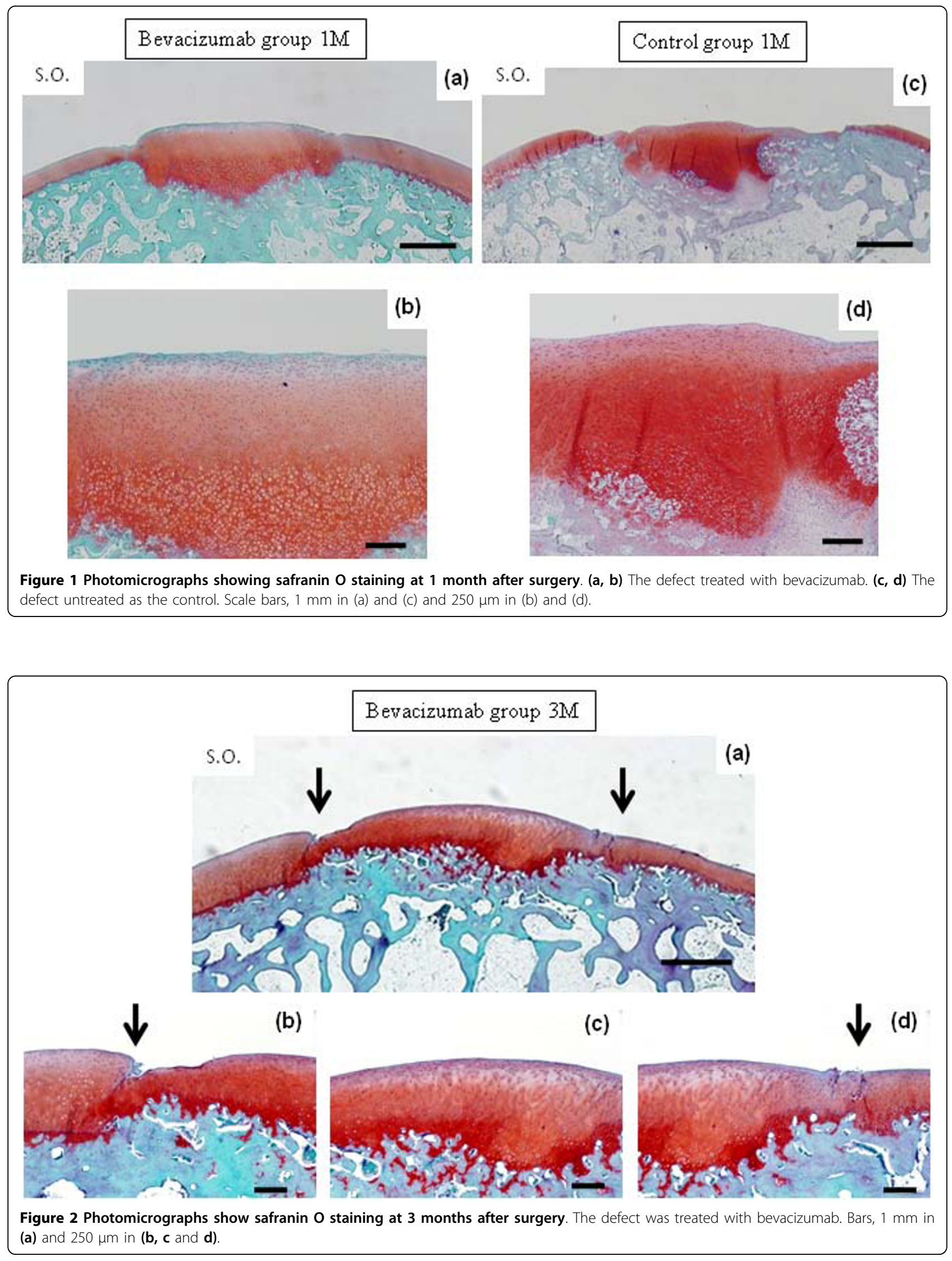


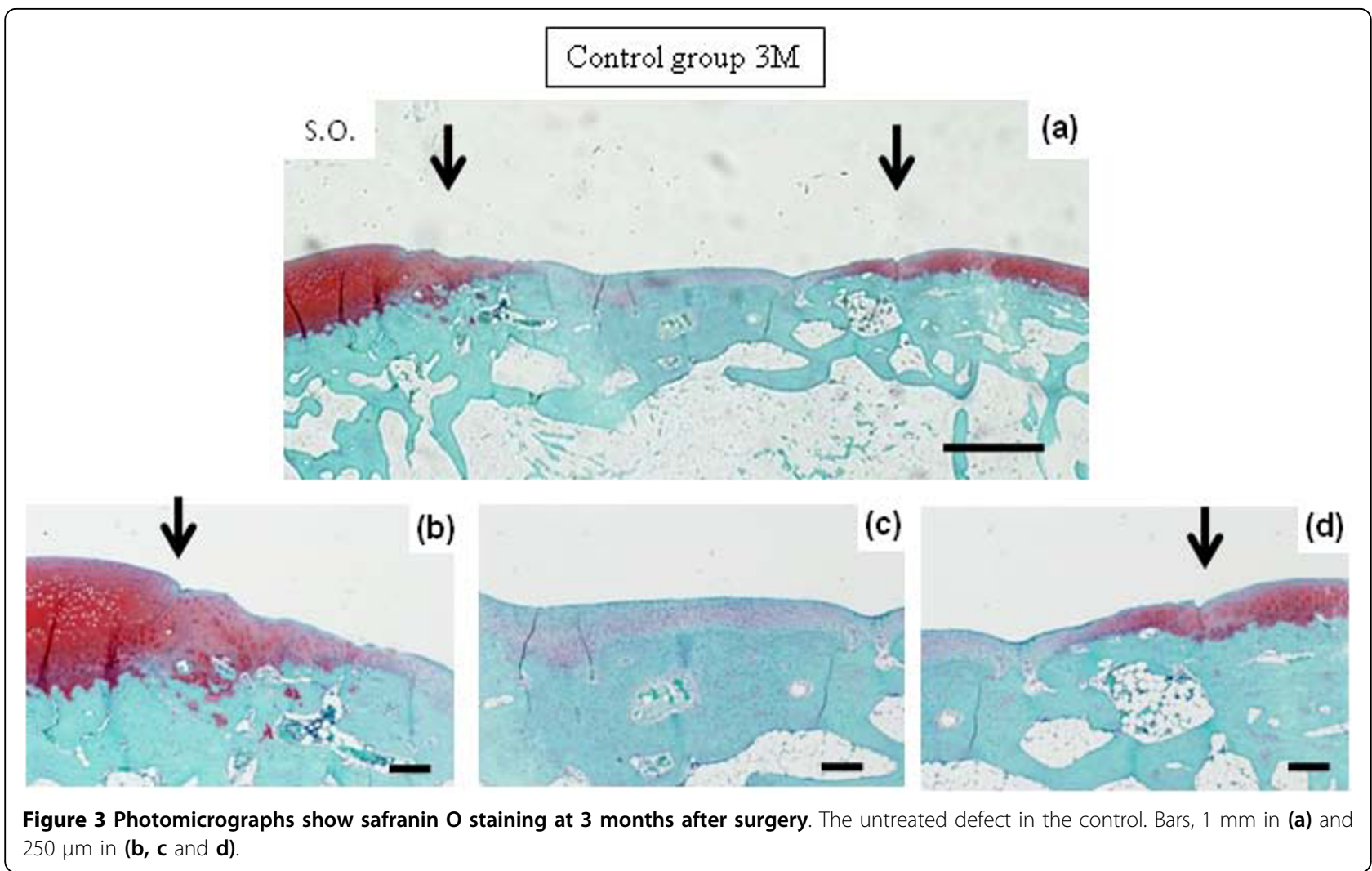

\section{Evaluation of $\mathrm{ChM}-\mathrm{I}$ and VEGF expression}

At 1 month, Group B showed intense positive results for ChM-I at the bottom of the repair tissue in the remodeling hypertrophic chondrocyte layer, representing the border between cartilage and bone (Figure 4a). ChM-I had accumulated in the interterritorial space of the repaired matrix (Figure 4a). In the controls, no ChM-I was observed in the repair tissue (Figure 4b). Conversely, the remodeling hypertrophic chondrocyte layer was intensely positive for VEGF in both Group B and in the controls (Figures 4c and 4d).

\section{Histological scoring of repair tissue}

We evaluated the repair site using a modified version of the grading system developed by O'Driscoll, Keeley and Salter [34]. In this system, 11 histologic categories were evaluated and scored: tissue morphology (Ti), matrix staining (Matx), structural integrity (Stru), cluster formation (Clus), tidemark opening (Tide), bone formation (Bform), histologic appraisal of surface architecture (SurfH), histologic appraisal of the degree of defect filling $(\mathrm{FilH})$, lateral integration of defect-filling tissue (Latl), basal integration of defect-filling tissue (Basl) and histologic signs of inflammation (InfH). The total score ranged from 11 (no repair) to 45 (normal articular cartilage) (Table 1).
At 1 month, inside the repair tissue in Group B, Ti was mostly hyaline cartilage in seven of nine cases, with high cellularity of rounded chondrocytes and mostly fibrocartilage in two of nine cases. Conversely, in the controls, 4 of 10 cases showed mostly hyaline cartilage, 4 of 10 cases were mostly fibrocartilage and 2 of 10 cases were mostly noncartilage. For Matx in Group B, six of nine cases were strong, two of nine cases were moderate and one case showed slight staining. In the controls, 5 of 10 cases were strong, 3 of 10 cases were moderate and 2 of 10 cases showed slight staining. In Group B, Stru of the defect filling revealed the beginning of columnar organization of chondrocytes in six of nine cases and no organization of chondrocytes in three of nine cases. In the controls, 3 of 10 cases showed the beginning of columnar organization, 4 of 10 cases showed no organization and 3 of 10 cases showed cysts or disruptions. In both groups, Clus was not observed except in one instance. In one instance, there was a small amount of Clus in both groups. Also, in both groups, Tide was opened in all instances. In Group B, subchondral Bform was not recognized in four of nine cases, slightly recognized in four of nine cases and strongly recognized in one of nine cases. In the control group, subchondral Bform was not recognized in 8 of 10 cases and was slightly recognized in 2 of 10 cases. 


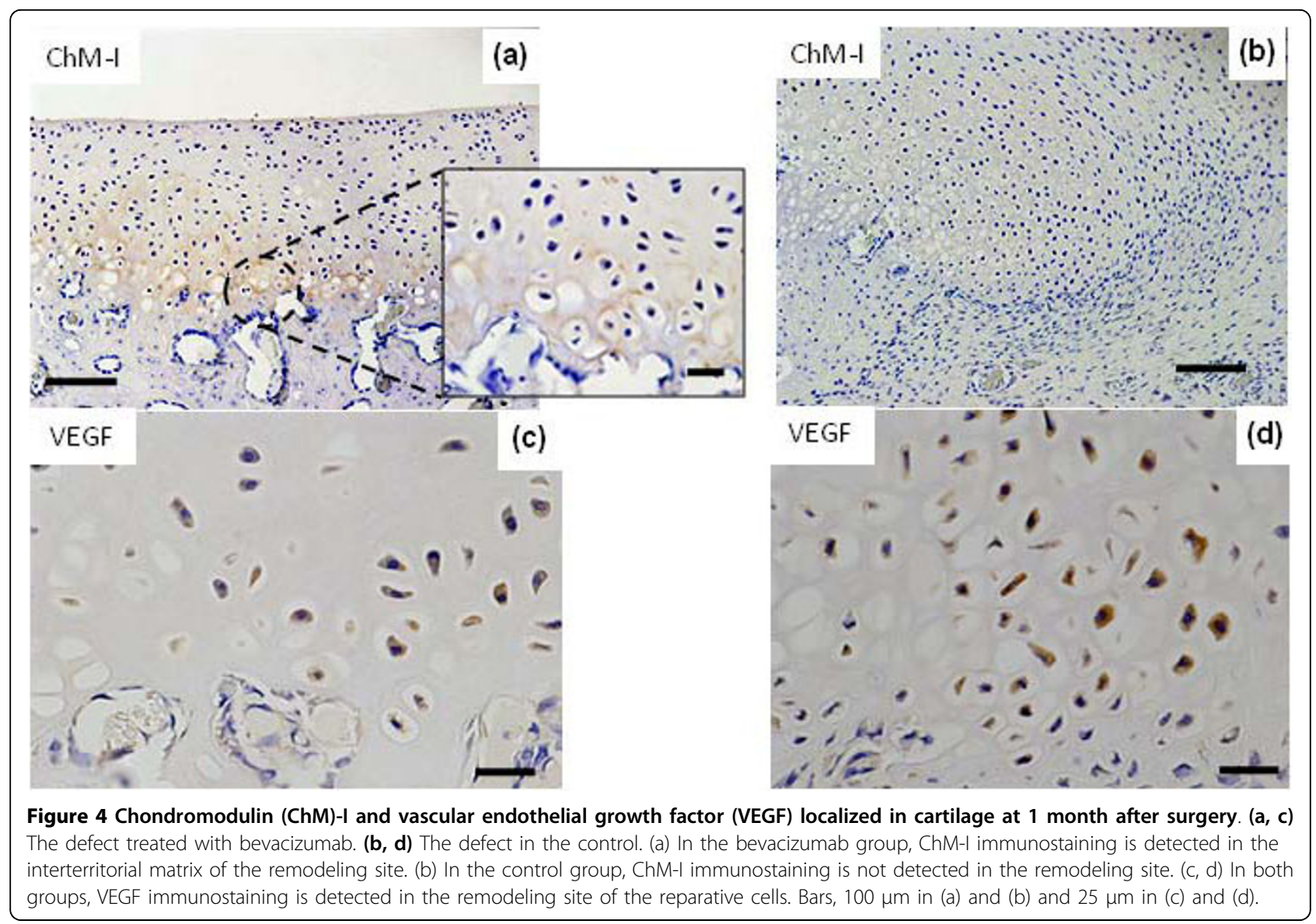

SurfH in Group B was normal in five of nine cases and showed slight fibrillation or irregularity in four of nine cases; in the control group, 1 of 10 cases was normal, 6 of 10 cases showed slight fibrillation or irregularity, 2 of 10 cases showed moderate fibrillation or irregularity and 1 of 10 cases showed severe fibrillation or disruption. FilH in Group B was complete in six of nine cases and nearly complete in three of nine cases. In controls, FilH was complete in 2 of 10 cases, nearly complete in 4 of 10 cases, moderate in 2 of 10 cases and nearly empty in 2 of 10 cases. Latl in Group B was bonded on both sides in seven of nine cases and bonded at one end or partially at both ends in two of nine cases. In controls, Latl was bonded on both sides in 1 of 10 cases, bonded at one end or partially at both ends in 6 of 10 cases and not bonded in 3 of 10 cases. Basl was good in all cases for both groups. In Group B, no inflammation was observed in all cases for InfH. The control group showed no inflammation in 5 of 10 cases, slight inflammation in 4 of 10 cases and strong inflammation in 1 of 10 cases. As a result, at 1 month, the total score was significantly higher for Group B than for the controls. In terms of individual scores, SurfH, FilH and Latl for Group B were significantly higher than in controls.
In Group B, Ti at 3 months showed mostly hyaline cartilage in six of seven cases. In one of seven cases, tissue was mostly fibrocartilage. Conversely, in the controls, 3 of 10 cases were mostly hyaline cartilage, with mostly fibrocartilage in 1 of 10 cases and exclusively noncartilage in 6 of 10 cases. For Matx, six of seven cases in Group B showed strong staining and one of seven cases showed moderate staining; in the controls, 3 of 10 cases were strong, one instance was moderate and 6 of 10 cases were nonstaining. In Group B, Stru of the defect filling revealed tissue similar to healthy mature cartilage in three of seven cases, beginning columnar organization of chondrocytes in three of seven cases and no organization of the chondrocytes in one of seven cases. In the controls, only one instance was similar to healthy mature cartilage, 2 of 10 cases were beginning columnar organization, 1 of 10 cases had no organization and 6 of 10 cases showed severe disintegration. In Group B, Clus was not observed. In controls, 2 of 10 cases showed no clusters, 2 of 10 cases showed some clusters and 6 of 10 cases showed abundant cluster cells or nonchondrocytes. Tide in Group B was complete in three of seven cases, nearly complete in two of seven cases, half degree in one of seven cases and nearly 
absent in one of seven cases; in the controls, 1 of 10 cases was complete, 2 of 10 cases were nearly complete, 1 of 10 cases was half degree and 6 of 10 cases were not recognized as containing a calcified cartilage layer. Bform was recognized in both groups, except for one instance in each. In one instance, there was a slightly Bform in both groups. SurfH in Group B was normal in five of seven cases and showed slight fibrillation or irregularity in two of seven cases; in the controls, 1 of 10 cases was normal, 1 of 10 cases showed slight fibrillation or irregularity, 2 of 10 cases showed moderate fibrillation or irregularity and 6 of 10 cases showed severe fibrillation or disruption. FilH in Group B was complete in all instances. In the controls, FilH was complete in 4 of 10 cases, moderate in 1 of 10 cases, nearly empty in 1 of 10 cases and almost empty in 4 of 10 cases. Latl in Group B were bonded at both sides in six of seven cases and bonded at one end in one of seven cases. In the controls, Latl was bonded both sides in 1 of 10 cases, bonded at one end or partially both ends in 2 of 10 cases and not bonded in 6 of 10 cases. Basl was good in all cases in both groups. For InfH, no inflammation was observed in any cases in either group. At 3 months, the total score for Group B was significantly higher than that for the controls. In terms of individual scores, $\mathrm{Ti}$, Matx, Stru, Clus, SurfH, FilH and Latl were significantly higher for Group B than for the control group (Table 2).

\section{Discussion}

VEGF is overexpressed in numerous solid angiogenic tumors and hematological malignancies. Interrupting the VEGF pathway has thus become a major focus of oncology research [35]. The first approved antiangiogenic therapy was bevacizumab, a humanized

Table 2 Histological scores for cartilage repair at 1 month and 3 months after surgery ${ }^{a}$

\begin{tabular}{lcccc}
\hline & \multicolumn{2}{c}{ 1 month } & \multicolumn{2}{c}{ 3 months } \\
\cline { 2 - 5 } & Group B & Control & Group B & Control \\
\hline $\mathrm{Ti}$ & $3.77 \pm 0.4$ & $3.20 \pm 0.7$ & $3.85 \pm 0.3^{*}$ & $2.10 \pm 1.4$ \\
Matx & $3.55 \pm 0.7$ & $3.30 \pm 0.8$ & $3.71 \pm 0.7^{*}$ & $2.10 \pm 1.4$ \\
Stru & $3.66 \pm 0.5$ & $3.00 \pm 0.8$ & $4.28 \pm 0.7^{*}$ & $2.41 \pm 1.6$ \\
Clus & $2.88 \pm 0.3$ & $2.90 \pm 0.3$ & $3.00 \pm 0.0^{*}$ & $1.60 \pm 0.8$ \\
Tide & $1.00 \pm 0.0$ & $1.00 \pm 0.0$ & $3.85 \pm 1.4$ & $2.20 \pm 1.6$ \\
Bform & $1.66 \pm 0.7$ & $1.20 \pm 0.4$ & $2.85 \pm 0.3$ & $2.90 \pm 0.3$ \\
SurfH & $3.55 \pm 0.5^{*}$ & $2.70 \pm 0.8$ & $3.71 \pm 0.4^{*}$ & $1.70 \pm 1.0$ \\
FilH & $4.66 \pm 0.5^{*}$ & $3.70 \pm 1.0$ & $5.00 \pm 0.0^{*}$ & $2.90 \pm 1.9$ \\
Latl & $2.77 \pm 0.4^{*}$ & $1.80 \pm 0.6$ & $2.85 \pm 0.3^{*}$ & $1.60 \pm 0.8$ \\
Basl & $4.00 \pm 0.0$ & $4.00 \pm 0.0$ & $4.00 \pm 0.0$ & $4.00 \pm 0.0$ \\
InfH & $5.00 \pm 0.0$ & $3.80 \pm 1.3$ & $5.00 \pm 0.0$ & $5.00 \pm 0.0$ \\
Hgtot & $36.55 \pm 2.1^{*}$ & $30.50 \pm 4.1$ & $40.14 \pm 2.5^{*}$ & $27.7 \pm 10.0$ \\
\hline
\end{tabular}

${ }^{a}$ Values are means \pm SD. The total score range is from 11 (no repair) to 45 (normal articular cartilage).

*Denotes significance at $P<0.05$. monoclonal anti-VEGF antibody. Following the success of a pivotal trial, the FDA approved bevacizumab for use in combination with intravenous 5-fluorouracilbased chemotherapy as a treatment for patients with first-line or previously untreated metastatic cancer of the colon or rectum [36]. Bevacizumab is anticipated to be useful not only for cancer treatment but also as a major advance in antiangiogenic therapy.

Generally, osteochondral defects have access to reparative cells of the bone marrow [37]. This connection allows infiltration of the bone by mesenchymal stem cells (MSCs) from the bone marrow, which can then proliferate and differentiate. MSC-derived chondrocytes subsequently appear during endochondral ossification and are invaded by the vasculature and marrow, and eventually the defects are replaced by subchondral bone $[28,38]$. In summary, MSC-derived chondrocytes are spontaneously recruited as reparative cells in osteochondral defects and are replaced by bone with high levels of vascular invasion. However, articular cartilage is a naturally avascular tissue, except during skeletal development, when endochondral bone formation occurs. We speculate that MSCs may use different courses of differentiation to become bone or cartilage, based on environmental differences in vascularization and avascularization. We recently reported that MSCs that acquire antiangiogenic properties achieve good cartilage restoration [23]. Furthermore, previous research has shown that VEGF expression by chondrocytes in osteoarthritic joints may be related to articular cartilage destruction [39-46]. High-dose VEGF may induce the onset and progression of arthritis [47,48]. Also, expression of high levels of VEGF during the terminal stages of chondrogenesis leads to endochondral ossification through angiogenesis $[49,50]$. We therefore studied the restoration of articular cartilage by blocking VEGF signaling with bevacizumab in a model of osteochondral defects in Japanese white rabbits.

At 1 month after surgery in both Group B and the controls, defects were recruited with reparative cells from the marrow and synovial tissue, and this was composed of differentiated chondrocytes, hyperchondrocytes and fibrous cells. These heterogeneous cells stained positive for safranin $\mathrm{O}$ and showed various levels of structured organization. From the surface, these structures consisted of a fibrous or fibrocartilage layer, a hyaline cartilage layer and a hypertrophic chondrocyte layer in both groups. As a result, no significant differences were apparent between the two groups at 1 month postoperatively in $\mathrm{Ti}$, Matx or Stru. However, at 1 month after surgery, the defects were repaired by hyaline cartilage (seven of nine cases) in Group B, a result of blocking VEGF, whereas in the controls, the defects were repaired with that of various tissues, including hyaline 
cartilage ( 4 of 10 cases), fibrocartilage ( 4 of 10 cases) and noncartilage ( 2 of 10 cases). There was no delay in subchondral bone formation in Group B when blocking VEGF. For autologous reparative cells, basal integration was good and most inflammatory signs were absent from both groups. On the other hand, FilH, Latl and SurfH were significantly higher for Group B than for the controls. Actually, at 1 month after surgery, six of nine cases in Group B showed convex surfaces of these repaired tissues in surrounding articular cartilage, compared to only 2 of 10 cases in the controls. These results indicate that blocking VEGF preserves the accumulation of reparative cells in the defect. This is supported by studies showing that VEGF treatment prevents condensation of chondrogenic mesenchyme during early limb bud development through abnormal vascularization [51]. As a sufficient number of reparative cells made contact with the surrounding cartilage layer, lateral integration was considered to be good. Also, repaired tissue taking a convex form consisted of a smoother surface than repaired tissue with a concave form.

Defects had been repaired by the formation of various tissues in the controls at 3 months after surgery, which included hyaline cartilage ( 3 of 10 cases), fibrocartilage ( 1 of 10 cases) and exclusively noncartilage (6 of 10 cases). On the other hand, when blocking VEGF, defects were repaired mostly with hyaline cartilage (six of seven cases), with only one case being mostly fibrocartilage. To emphasize this, no cases showed replacement by fibrous tissue or bone. Similarly, 1 month after surgery, the controls showed repair without consistent tissue morphology, while Group B showed repair with consistency of tissue morphology. At 3 months postoperatively, Ti, Matx, Stru and Clus were significantly higher for Group B than for the controls. In both Group B and the controls, Tide was generally closed and bone formation was gradually observed. Continuous basal integration was also good and most signs of inflammation were not apparent in either group. Tissue that was repaired in the form of fibrous tissue and bone tended to show moderate or severe fibrillation of surface architecture and low defect filling. Therefore, SurfH and FilH were significantly higher for Group B than for the controls. As mentioned before, a sufficient number of reparative cells were in contact with the surrounding cartilage layer, and lateral integration was considered to be good. As a result, at 3 months, the total score was significantly higher for Group B than for the controls.

Interestingly, ChM-I was expressed in the early stage of tissue repair after bevacizumab administration. ChMI reportedly stimulates chondrocyte proliferation and proteoglycan synthesis in vitro and inhibits proliferation of vascular endothelial cells in vitro and in vivo $[52,53]$. Kitahara et al. [53] suggested that in their mouse model,
ChM-I acts to inhibit vascular invasion in the immature state of articular cartilage, and levels of ChM-I gradually decrease with age thereafter. Hiraki et al. [52] reported that ChM-I is expressed in the avascular zone of cartilage in developing bone, but is not present in calcifying cartilage. Such findings suggest a regulatory role of ChM-I in vascular invasion during endochondral bone formation.

In this study, ChM-I was expressed at the bottom of the repair site invaded near the vasculature. ChM-I accumulated in the interterritorial space of the repaired matrix and was surrounding the cells that expressed VEGF. ChM-I is thought to form a barrier to inhibit vascular invasion from subchondral bone, indicating that it facilitates the acquisition of articular cartilage through the process of MSC differentiation in endochondral ossification. However, the shift from angiogenesis to antiangiogenesis is not determined entirely by ChM-I and VEGF. Inducers of endogenous angiogenic molecules also exist in the process of endochondral ossification, and these include VEGF [53], fibroblast growth factor 2 [54], transforming growth factor [55] and tissue matrix metalloprotease 9 [56].

In other studies, VEGF has been reported to be necessary for chondrocyte survival during cartilage development. In VEGF-deficient mouse models, massive cell death is observed in the joint and epiphyseal regions of cartilage during cartilage development $[57,58]$. In this study, we blocked VEGF temporarily to initiate reparative cells. To avoid complete inhibition of the bioactivity of VEGF in reparative cells, we blocked VEGF on the day of surgery and 2 weeks later. As a result, 1 month after surgery, reparative cells actually expressed VEGF in Group B (Figure 4c). Moreover, expression of ChM-I as an antiangiogenic factor was observed in the layer of reparative cells involved in blood vessel invasion from subchondral bone (Figure 4a). It is important to consider the efficacy of various VEGF treatments in the balance of angiogenesis-antiangiogenesis during chondrogenic differentiation of MSC-derived reparative cells. In other words, repair of articular cartilage may be achievable by adjusting optimal VEGF signaling. In a recent study, Kubo et al. [39] reported good cartilage restoration using muscle-derived stem cells that transfected with the genes of Flt-1 (a VEGF antagonist) and bone morphogenetic protein (BMP) 4 in a mouse osteochondral defect model. However, the techniques applied in that study were complicated, as they required isolation of stem cells from muscular tissue, gene transduction and cell culture in vitro, as well as cell transplantation. Conversely, the present technique involves the simple means of achieving cartilage restoration by intravenous administration of bevacizumab, a treatment already cleared for clinical application. Hence, 
this method would be applicable in many medical facilities. Thus, vascularization of the tissue environment after injury or degeneration would be improved to a more advantageous situation of cartilage repair if VEGF were blocked. Accordingly, without depending on cells or tissue transplantation, this approach would augment the curative effects of existing approaches such as microfracture or drilling.

The half-life of bevacizumab in the circulation of humans is reportedly 17-21 days. The approved dose of bevacizumab in humans is $5 \mathrm{mg} / \mathrm{kg}$, and the clinical administration interval is more than 2 weeks [30]. Bevacizumab is cross-reactive with rabbit VEGF, but has eightfold lower affinity for rabbit VEGF than for human VEGF [59]. Therefore, in this study, we investigated bevacizumab at the dose of $40 \mathrm{mg} / \mathrm{kg}$ administered on the day of surgery and 2 weeks later. As a future consideration, we plan to investigate the dosage and duration of bevacizumab administration. We will also address the side effects of infection by applying minimally invasive surgery with an arthroscope and using antibiotics.

\section{Conclusions}

Temporary intravenous administration of the humanized monoclonal anti-VEGF antibody bevacizumab in an osteochondral defect model results in positive restorative effects. We suggest that this approach would be useful to achieve repair of articular cartilage without the need for cells or tissue transplantation.

\begin{abstract}
Abbreviations
BASL: basal integration of defect-filling tissue; BFORM: bone formation; BMP: bone morphogenetic protein; BSA: bovine serum albumin; CHM-I:

chondromodulin-l; CLUS: cluster formation; EDTA: ethylenediaminetetraacetic acid; FILH: histologic appraisal of the degree of defect filling; ICRS:

International Cartilage Repair Society; INFH: histologic signs of inflammation; LATL: lateral integration of defect-filling tissue; MATX: matrix staining; PBS: phosphate-buffered saline; SD: standard deviation; STRU: structural integrity; SURFH: histologic appraisal of surface architecture; TI: tissue morphology; TIDE: tidemark opening; VEGF: vascular endothelial growth factor.
\end{abstract}

\section{Acknowledgements}

This research was partly supported by Grants-In-Aid for Scientific Research from the Ministry of Education, Culture, Sports, Science and Technology of Japan, and Mitsui Sumitomo Insurance Welfare Foundation.

\section{Authors' contributions}

TN and MS performed most of the experiments and MK performed the immunohistochemistry. TK, GE and NO helped with in vivo experiments. TN performed statistical analyses. MS and JM designed and coordinated the study and helped draft the manuscript. All authors approved the final manuscript.

\section{Competing interests}

The authors declare that they applied for a patent relating to the content of the manuscript in Japan, but did not receive any reimbursements, fees, funding or salary from an organization. The competitive companies developing or selling anti-VEGF drugs (e.g., Novartis, Wyeth, Bayer Schering) may keep them in check.
Received: 17 May 2010 Revised: 31 July 2010

Accepted: 24 September 2010 Published: 24 September 2010

\section{References}

1. Paget J: Healing of cartilage. Clin Orthop Relat Res 1969, 64:7-8.

2. Pridie KH: A method of resurfacing osteoarthritic knee joints. J Bone Joint Surg Br 1959, 41:618-619.

3. Muller B, Kohn D: Indication for and performance of articular cartilage drilling using the Pridie method. Orthopade 1999, 28:4-10.

4. Insall JN: Intra-articular surgery for degenerative arthritis of the knee. A report of the work of the late K. H. Pridie. J Bone Joint Surg Br 1967, 49:211-228.

5. Insall J: The Pridie debridement operation for osteoarthritis of the knee. Clin Orthop 1974, 101:61-67.

6. Steadman J, Rodkey W, Briggs K, Rodrigo J: The microfracture technique in the management of complete cartilage defects in the knee joint. Orthopade 1999, 28:26-32.

7. Steadman J, Rodkey W, Rodrigo J: Microfracture: surgical technique and rehabilitation to treat chondral defects. Clin Orthop Relat Res 2001, , 391 Suppl: S362-S369.

8. Steadman J, Rodkey W, Briggs K: Microfracture to treat full-thickness chondral defects: surgical technique, rehabilitation, and outcomes. J Knee Surg 2002, 15:170-176.

9. Mithoefer K, Williams RJ, Warren RF, Potter HG, Spock CR, Jones EC, Wickiewicz TL, Marx RG: Chondral resurfacing of articular cartilage defects in the knee with the microfracture technique: surgical technique. $J$ Bone Joint Surg Am 2006, 88:294-304.

10. Hangody L, Kish G, Karpati Z, Udvarhelyi I, Szerb I, Bely M: Autogenous osteochondral graft technique for replacing knee cartilage defects in dogs. Orthopedics 1997, 5:175-181.

11. Hangody L, Feczko P, Bartha L, Bodo G, Kish G: Mosaicplasty for the treatment of articular defects of the knee and ankle. Clin Orthop Relat Res 2001, , 391 Suppl: S328-S336.

12. Szerb I, Hangody L, Duska Z, Kaposi NP: Mosaicplasty: long-term followup. Bull Hosp Jt Dis 2005, 63:54-62.

13. Brittberg M, Lindahl A, Nilsson A, Ohlsson C, Isaksson O, Peterson L: Treatment of deep cartilage defects knee with autologus chondrocyte transplantation. N Engl J Med 1994, 331:889-895.

14. Peterson $L$, Minas T, Brittberg M, Lindahl A: Treatment of osteochondritis dissecans of the knee with autologouschondrocyte transplantation: results at two to ten years. J Bone Joint Surg Am 2003, 85-A Suppl 2:17-24.

15. Zaslav K, Cole B, Brewster R, DeBerardino T, Farr J, Fowler P, Nissen C, STAR Study Principal Investigators: A prospective study of autologous chondrocyte implantation in patients with failed prior treatment for articular cartilage defects of the knee: results of the Study of the Treatment of Articular Repair (STAR) clinical trial. Am I Sports Med 2009, 37:42-55.

16. Moseley JB Jr, Anderson AF, Browne JE, Mandelbaum BR, Micheli $L$, Fu F, Erggelet C: Long-term durability of autologus chondrocyte implantation: a multicenter, observational study in US patients. Am J Sports Med 2010, 38:238-46.

17. Darling EM, Athanasiou KA: Articular cartilage bioreactor and bioprocess. Tissue Eng 2003, 9:9-26.

18. Backwalter JA, Lohmander S: Operative treatment of osteoarthrosis. Current practice and future development. J Bone Joint Surg Am 1994, 76:1405-1418.

19. Freed $L E$, Grande $D A$, Lingbin Z, Emmanual J, Marquis JC, Langer R: Joint resurfacing using allograft chondrocytes and synthetic biodegradable polymer scaffolds. J Biomed Mater Res 1994, 28:891-899.

20. Hunziker EB: Articular cartilage repair: basic science and clinical progress. A review of the current status and prospects. Osteoarthritis Cartilage 2002, 10:432-463.

21. Marcacci M, Berruto M, Brocchetta D, Delcogliano A, Ghinelli D, Gobbi A, Kon E, Pederzini L, Rosa D, Sacchetti GL, Stefani G, Zanasi S: Articular cartilage engineeiring with Hyalograft C: 3-year clinical results. Clin Orthop Relat Res 2005, 435:96-105.

22. Crawford DC, Heveran CM, Cannon WD Jr, Foo LF, Potter HG: An autologus cartilage tissue implant NeoCart for treatment of grade III chondral injury to the distal femur: prospective clinical safety trial at 2 years. Am J Sports Med 2009, 37:1334-1343. 
23. Nagai T, Sato M, Furukawa KS, Kutsuna T, Ohta N, Ushida T, Mochida J: Optimization of allograft implantation using scaffold-free chondrocyte plates. Tissue Eng Part A 2008, 14:1225-1235.

24. Nagai T, Furukawa KS, Sato M, Ushida T, Mochida J: Characteristics of a scaffold-free articular chondrocyte plate grown in rotational culture. Tissue Eng Part A 2008, 14:1183-1193.

25. Mainil-Varlet P, Rieser F, Grogan S, Mueller W, Saager C, Jakob RP: Articular cartilage repair using a tissue-engineered cartilage-like implant: an animal study. Osteoarthritis Cartilage 2001, 9 Suppl A:S6-S15.

26. Brehm W, Aklin B, Yamashita T, Rieser F, Trub T, Jakob RP, Mainil-Varlet P: Repair of superficial osteochondral defects with an autologous scaffoldfree cartilage construct in a caprine model: implantation method and short-term results. Osteoarthritis Cartilage 2006, 14:1214-1226.

27. Park K, Huang J, Azar F, Jin RL, Min BH, Han DK, Hasty K: Scaffold-free, engineered porcine cartilage construct for cartilage defect repair: in vitro and in vivo study. Artif Organs 2006, 30:586-596.

28. Caplan Al, Elyaderani M, Mochizuki Y, Wakitani S, Goldberg VM: Principles of cartilage repair and regeneration. Clin Orthop Relat Res 1997, 342:254-272

29. Nagai T, Sato M, Furukawa KS, Kutsuna T, Ohta N, Ushida T, Mochida J: Repair of total thickness defect of articular cartilage with scaffold-free chondrocyte plate. Proceedings of 55th Annual Meeting, Orthopaedic Research Society, 22-25 February Las Vegas, NV, USA 2009.

30. Herbert H, Louis F, William N, Thomas C, John H, William H, Jordan B, Ari B, Susan G, Eric H, Napoleone F, Gwen F, Beth R, Robert R, Fairooz K: Bevacizumab plus Irinotecan, Fluorouracil, and Leucovorin for metastatic colorectal cancer. N Engl J Med 2004, 350:2335-2342.

31. Jain RK: Normalizing tumor vasculature with anti-angiogenic therapy: a new paradigm for combination therapy. Nat Med 2001, 7:987-989.

32. Willet CG, Boucher Y, Di Tomaso E, Duda DG, Munn LL, Tong RT, Chung DC, Sahani DV, Kalva SP, Kozin SV, Mino M, Cohen KS, Scadden DT, Hartford AC, Fischman AJ, Clark JW, Ryan DP, Zhu AX, Blaszkowsky LS, Chen HX, Shellito PC, Lauwers GY, Jain RK: Direct evidence the VEGFspecific antibody bevacizumab has antivascular effects in human rectal cancer. Nat Med 2004, 10:145-147.

33. Hayami T, Funaki H, Yaoeda K, Mitui K, Yamagiwa $H$, Tokunaga $K$, Hatano $H$, Kondo J, Hiraki Y, Yamamoto T, Duong le T, Endo N: Expression of the cartilage derived anti-angiogenic factor chondromodulin-I decreases in the early stage of experimental osteoarthritis. J Rheumatol 2003, 30:2207-2217.

34. O'Driscoll SW, Keeley FW, Salter RB: Durability of regenerated articular cartilage produced by free autogenous periosteal grafts in major fullthickness defects in joint surfaces under the influence of continuous passive motion: a follow-up report at one year. J Bone Joint Surg Am 1998, 70:595-606.

35. Eskens FA: Angiogenesis inhibitors in clinical development. $\mathrm{Br} J$ Cancer 2004, 90:1-7.

36. Branavan S, Lorraine EH, Ewa MP: Modulation angiogenesis. JAMA 2004, 292:972-977

37. Solchaga LA, Yoo JU, Lundberg M, Dennis JE, Huibregtse BA, Goldberg VM, Caplan Al: Hyaluronan-based polymers in the treatment of osteochondral defects. J Orthop Res 2000, 18:773-780.

38. Shapiro F, Koide S, Glimcher MJ: Cell origin and differentiation in the repair of full-thickness defects of articular cartilage. J Bone Joint Surg Am 1993, 75:532-553.

39. Kubo S, Cooper GM, Matsumoto T, Phillippi JA, Corsi KA, Usas A, Li G, Fu FH, Huard J: Blocking vascular endothelial growth factor with soluble Flt-1 improves the chondrogenic potential of mouse skeletal musclederived stem cells. Arthritis Rheum 2009, 60:155-165.

40. Hashimoto S, Ochs RL, Komiya S, Lotz M: Linkage of chondrocyte apoptosis and cartilage degradation in human osteoarthritis. Arthritis Rheum 1998, 41:1632-1638.

41. Hashimoto S, Creighton-Achermann L, Takahashi K, Amiel D, Coutts RD, Lotz M: Development and regulation of osteophyte formation during experimental osteoarthritis. Osteoarthritis Cartilage 2002, 10:180-187.

42. Enomoto H, Inoki I, Komiya K, Shiomi T, Ikeda E, Obata K, Matsumoto H, Toyama Y, Okada Y: Vascular endothelial growth factor isoforms and their receptors are expressed in human osteoarthritic cartilage. Am J Pathol 2003, 162:171-181

43. Tanaka E, Aoyama J, Miyauchi M, Takata T, Hanaoka K, Iwabe T, Tanne K: Vascular endothelial growth factor plays an important autocrine/ paracrine role in the progression of osteoarthritis. Histochem Cell Biol 2005, 123:275-281.

44. Pufe T, Petersen W, Tillmann B, Mentlein R: The splice variants VEGF121 and VEGF189 of the angiogenic peptide vascular endothelial growth factor are expressed in osteoarthritic cartilage. Arthritis Rheum 2001, 44:1082-1088.

45. Pufe T, Harde V, Petersen W, Goldring MB, Tillmann B, Mentlein R: Vascular endothelial growth factor (VEGF) induces matrix metalloproteinase expression in immortalized chondrocytes. J Pathol 2004, 202:367-374.

46. Pufe T, Lemke A, Kurz B, Petersen W, Tillmann B, Grodzinsky AJ, Mentlein R: Mechanical overload induces VEGF in cartilage discs via hypoxiainducible factor. Am J Pathol 2004, 164:185-192.

47. Murakami M, Iwai S, Hiratsuka S, Yamauchi M, Nakamura K, Iwakura Y, Shibuya M: Signaling of vascular endothelial growth factor receptor-1 tyrosine kinase promotes rheumatoid arthritis through activation of monocytes/macrophages. Blood 2006, 108:1849-1856.

48. Afuwape $A O$, Kiriakidis $S$, Paleolog EM: The role of the angiogenic molecule VEGF in the pathogenesis of rheumatoid arthritis. Histol Histopathol 2002, 17:961-972.

49. Gerber HP, Vu TH, Ryan AM, Kowalski J, Werb Z, Ferrara N: VEGF couples hypertrophic cartilage remodeling, ossification and angiogenesis during endochondral bone formation. Nat Med 1999, 5:623-628.

50. Carlevaro MF, Cermelli S, Cancedda R, Descalzi Cancedda F: Vascular endothelial growth factor (VEGF) in cartilage neovascularization and chondrocyte differentiation: auto-paracrine role during endochondral bone formation. J Cell Sci 2000, 113:59-69.

51. Yin M, Pacifici $M$ : Vascular regression is required for mesenchymal condensation and chondrogenesis in the developing limb. Dev Dyn 2001, 222:522-533

52. Hiraki $Y$, Inoue $H$, lyama $K$, Kamizono A, Ochiai M, Shukunami $C$, lijima $S$, Suzuki F, Kondo J: Identification of chondromodulin I as a novel endothelial cell inhibitor: purification and its localization in the avascular zone of epiphyseal cartilage. J Biol Chem 1997, 272:32419-32426.

53. Kitahara H, Hayami T, Tokunaga K, Endo N, Funaki H, Yoshida Y, Yaoita E, Yamamoto T: Chondromodulin-I expression in rat articular cartilage. Arch Histol Cytol 2003, 66:221-228.

54. Gonzalez AM, Buscaglia M, Ong M, Baird A: Distribution of basic fibroblast growth factor in the 18-day rat fetus: localization in the basement membranes of diverse tissues. J Cell Biol 1990, 110:753-765.

55. Gelb DE, Rosier RN, Puzas JE: The production of transforming growth factor-beta by chick growth plate chondrocytes in short term monolayer culture. Endocrinology 1990, 127:1941-1947.

56. Thiennu HV, Shipley JM, Bergers G, Burger JE, Helms JA, Hanahan D, Shapiro SD, Senior RM, Werb Z: MMP-9/Gelatinase B is a key regulator of growth plate angiogenesis and apoptosis. Cell 1998, 93:411-422.

57. Zelzer E, Mamluk R, Ferrara N, Johnson RS, Schipani E, Olsen BR: VEGFA is necessary for chondrocyte survival during bone development. Development 2004, 131:2161-2171.

58. Haigh JJ, Gerber HP, Ferrara N, Wagner EF: Conditional inactivation of VEGF-A in areas of collagen2a1 expression results in embryonic lethality in the heterozygous state. Development 2000, 127:1445-1453.

59. Van der Flier M, Coenjaerts FE, Mwinzi PN, Rijkers E, Ruyken M, Scharringa J, Kimpen JLL, Hoepelman AIM, Geelen SPM: Antibody neutralization of vascular endothelial growth factor (VEGF) fails to attenuate vascular permeability and brain edema in experimental pneumococcal meningitis. J Neuroimmunol 2005, 160:170-177.

doi:10.1186/ar3142

Cite this article as: Nagai et al.: Intravenous administration of antivascular endothelial growth factor humanized monoclonal antibody bevacizumab improves articular cartilage repair. Arthritis Research \& Therapy 2010 12:R178. 